\title{
Secondary Forest Age Mapping in Amazônia using Multi-Temporal Landsat/TM Imagery
}

\author{
Sidnei J. S. Sant'Anna \\ Corina da Costa Freitas Yanasse \\ Pedro Hernandez Filho \\ Tatiana Mora Kuplich \\ Luciano Vieira Dutra \\ Alejandro C. Frery \\ Patricia Pessôa dos Santos \\ INPE - Instituto Nacional de Pesquisas Espaciais \\ DPI — Divisão de Processamento de Imagens \\ Avenida dos Astronautas, 1758 \\ 12227-010 São José dos Campos \\ SP - BRAZIL \\ T: +55 123418977 Ext. 533 F: +55 123218743
}

Abstract - Satellite imagery can be a powerful tool for identification of deforested areas, often providing reliable classification of the earth surface. The aim of this paper is to identify and to characterize the age of tropical secondary forests in a test site near Tapajós National Forest, located on the south of Santarém city, Pará State, Brazil, using a time series of Landsat/ TM images. The Landsat/TM images from 1986 to 1992 were co-registered, segmented and classified into several classes of land cover. These thematic images were superposed in a GIS and, using logical (Boolean) operations, a stages of regeneration map was generated. The stages of regeneration classes were defined as areas with recent activities, areas with different stages of secondary vegetation (varying from one to six years of regeneration), old secondary forest (more than six years old), and primary forest. It was observed that there is a functional relationship between the stages of the classified secondary vegetation and the normalized difference vegetation index (NDVI) using the bands 3 and 4 of the Landsat/TM images. It was concluded that the use of time series of optical images can be a valuable tool for determining the evolution of secondary tropical forests, providing that image acquision is possible at least once a year.

\section{INTRODUCTION}

The Tapajos National Forest is managed by the Brazilian Institute for Environment and Natural Renewable Resources (IBAMA). It is located in Santarém City, Pará State, Brazil, between the parallels $02^{\circ} 40^{\prime}$ to $04^{\circ} 10^{\prime}$ (South) and the meridians $54^{\circ} 45^{\prime}$ to $55^{\circ} 00^{\prime}$ (West). It borders on the north with a line that joins the Santarém-Cuiabá Highway on the $\mathrm{km} 50$ and the point with latitude $02^{\circ} 45^{\prime} \mathrm{S}$ of the Tapajós River; on the east with the Santarém-Cuiabá Highway up to the km 205; on the south with the Santa Cruz and Cupari rivers; on the west with the Tapajós River. In the last few decades the Brazilian Tropical Forest has presented dynamic alterations, resulting from human disturbance due to the installation of farm for agriculture and cattle raising, and to the implantation of several settlement projects.

Many of these areas have been abandoned, and their vegetation is presently under regeneration by secondary succession. Not much is known about the extension, location and stage of the regeneration of these areas. The study of the stages of secondary forests is justified by the impact that these areas have in the regional carbon budget which may have consequences on the global climate change and in the carbon storage in the atmosphere. In this paper a multitemporal LANDSAT/TM sequence of images was used aiming at the obtainment of a regeneration stages map. The applied methodology is described in the following sections, and the main results are presented for an approximately squared area of about $12.5 \mathrm{~km}$ of size; the geographic coordinates of its diagonal are given by $\left(03^{\circ} 03^{\prime} 23^{\prime \prime} \mathrm{S}, \quad 55^{\circ} 01^{\prime} 45^{\prime \prime} \mathrm{W}\right)$ and $\left(03^{\circ} 10^{\prime} 08^{\prime \prime} \mathrm{S}\right.$, $54^{\circ} 55^{\prime} 00^{\prime \prime} \mathrm{W}$ ).

\section{DATA USED AND METHODOLOGY}

The following data sets and computational support were used in order to obtain the regeneration stages map:

- cartographic chart at 1:250.000 scale;

- LANDSAT/TM images, bands 3, 4 and 5, from years 1986 to 1992 ;

- SPRING (Georeferenced Informations Processing System), under development at DPI/INPE.

\subsection{Registration}

The first step consisted of making a registration of the 1991 TM image (band 3) with the cartographic chart; the final spatial resolution was of $25 \times 25 \mathrm{~m}$. The remaining images were image-to-image registered, having the 1991 TM band 3 image as reference and the same spatial resolution.

The number of control points involved in the registration process varied from 7 to 12 , whilst the errors ranged from $8.9 \mathrm{~m}$ to $16.175 \mathrm{~m}$.

In Fig. 1 the first principal component (after histogram equalization) of bands 3, 4 and 5 (1992 TM image) of the study area is shown. This image has $416 \times 418$ pixels.

\subsection{Segmentation}

The segmentation process used was a region growing procedure consisting on the aggregation of pixels with similar properties in sets called segments, defined by their borders. In this work the algorithm proposed in [1] was used to extract a suitable set of borders. This algorithm considers that a region is a set of spatially connected sites with radiometries exhibiting some kind of homogeneity (for instance, with respect to their mean, variance, perimeter, area, etc.). The use of this technique requires the definition of two thresholds:

- Similarity threshold: a value below which two regions are considered similar, and then merged in a new region; this threshold is defined by the minimum Euclidean distance between the means of the considered regions.

- Area threshold: minimum number of pixels required to form a region.

The result of applying this algorithm to an image is a symbolic representation of the input: a list of regions with their attributes, a list of arcs (borders between two regions) with their attributes (strength and mean border orientation) and a list of nodes (points where three or more regions meet). 
This technique was applied, separately, to all the seven three-band images corresponding to the aforementioned dates (1986 to 1992).

\subsection{Segments classification}

This step identifies and labels segments with similar properties using a clustering algorithm called ISOSEG [1], which is a kind of region classifier.

This classification was performed in three stages:

- Feature extraction: the means vector and covariance matrix of every region previously defined in the segmentation process were calculated, considering all the desired bands (3, 4 and 5 , for this work).

- Identification and colouring: similar segments are identified, and a single colour is attributed to them by the clustering algorithm. An accepting threshold is used in this stage, which defines the maximum Mahalanobis distance between regions, as well as the number of clusters to be detected by the algorithm.

- Geoclasses labelling: the identified and coloured regions are associated to the previously defined geoclasses.

This procedure was applied to the seven segmented images already obtained, generating seven thematic images. In this work the defined six geoclasses are associated to land use and vegetation types: (i) primary forest, (ii) secondary vegetation and pasture, (iii) new secondary vegetation, (iv) pasture and bare soil, (v) bare soil, (vi) river, and a nuisance type (vii) shadows and clouds.

For every coordinate from date $i, 1 \leq i \leq 7$, denote the classified value $x_{i} \in\left\{c_{1}, \ldots, c_{7}\right\}$, where $c_{j}$ is the $j$-th geoclass. For instance $x_{3}=c_{1}$ means that the considered pixel was classified as primary forest $\left(c_{1}\right)$ in $1988(i=3)$.

\subsection{Regeneration stages mapping}

The thematic images already obtained were combined, in a pixel-to-pixel Boolean basis, to form a thematic map reflecting age-related areas. The classes, in this map, were defined as areas with recent activities, areas with different stages of secondary vegetation (varying from one to six years of regeneration), old secondary forest (more than six years old), and primary forest.

Consider the following example: $x_{1}=x_{2}=x_{3}=x_{4}=c_{1}$, $x_{5}=c_{5}$ and $x_{6}=x_{7}=c_{2}$; this pixel will be mapped into the two years old regeneration class. Inconsistencies as, for instance, $x_{i}=c_{5}, x_{i+1}=c_{1}$ (i.e. bare soil followed by primary forest) are properly treated by the set of logical rules and assigned to an uninformative class.

In Fig. 3 a map of stages of regeneration is shown, where a grouping of similar classes was performed, in order to reduce classification errors.

\subsection{Relating stages of regeneration map and TM data}

Based on the stages of regeneration thematic map, the normalized difference vegetation index (NDVI) was calculated over the 1992 Landsat/TM images, conditioned to the age classes; only pixels having their eight neiboours belonging to the same class were considered, to reduce misclassification bias.

\section{RESULTS AND CONCLUSIONS}

The 1992 image classification was evaluated [2] by comparing samples from the classified image (C) with samples from a visual interpretation (V), using 133 samples of different classes. The confusion matrix is given by:

\begin{tabular}{|c|c|c|c|c|c|c|}
\hline C $\backslash V$ & (i) & (ii) & (iii) & (iv) & (v) & Total \\
\hline (i) & 10 & 3 & 0 & 0 & 0 & 13 \\
\hline (ii) & 1 & 26 & 2 & 2 & 0 & 31 \\
\hline (iii) & 0 & 4 & 1 & 8 & 0 & 13 \\
\hline (iv) & 0 & 2 & 1 & 14 & 6 & 23 \\
\hline (v) & 0 & 0 & 0 & 2 & 51 & 53 \\
\hline Total & 11 & 35 & 4 & 26 & 57 & 133 \\
\hline
\end{tabular}

Most errors occurred with the new secondary vegetation classification, probably because it may come out as a result of several types of abandoned areas like pasture, agricultural, bare soil, etc. The correct percentage of agreement is $77 \%$ (sum of correct classifications/133). The Kappa coefficient of agreement was also used for evaluating the classification, achieving the value of 67.76 , with a variance of the 0.0023 . This evaluation was only performed on the 1992 image due to the lack of information from other (previous) dates.

The NDVI image was computed from the 1992 TM data, and the average gray level, as a function of the secondary stages, was calculated (see Fig. 2, where the error bars equal one standard error). It must be noticed that the time scale is not homogeneous, although the regeneration stages are plotted in an equally spaced manner. The four first points are equally spaced in time, every interval reflecting two years; the fifth point is a mean over all regeneration stages that are more than six years old. The last point, corresponding to primary forest, could be understood as a mean calculated over areas which were allowed to regenerate an infinite number of years.

It can be observed that the NDVI follows the same pattern as that from several agricultural crops in growing stage. The NDVI value is increasing until, at least, the regeneration is between five and six years of regeneration (fourth point). The highest NDVI occurs after five years of regeneration, followed by decreasing values until reaching the primary forest response. This decrease (related in the image with dominating trees shadows) might be due to the canopy heterogeneity.

The verification of the overall accuracy of the presented results is not an easy task since, among other reasons, it is very difficult to obtain precise information - from any sourceabout the areas history. Notice, though, that consistency in the behaviour of the NDVI was observed.

\section{EXTENSIONS AND FUTURE WORK}

The use of time series of optical images showed its potential in the determination of the evolution of secondary forests in Amazônia. This potentiality can be fully exploited provided image acquisition is possible at least once a year.

This study will continue by examining the relationship between the stages of regeneration and biomass of secondary forests with the backscatter from different bands and polarizations of radar sensors. Some preliminary results, concerning the relationship between the stages of regeneration and ERS-1 data are presented in [3].

More precise information about areas history will be sought.

\section{ACKNOWLEDGMENT}

The authors are grateful to Yosio Shimabukuro and Dalton Morrison Valeriano (INPE - DSR) for their support and fruitful discussions. This paper was partially supported by FAPESP (Fundação de Amparo à Pesquisa do Estado de São Paulo, Brazil) Project No. 91/3532-2. 


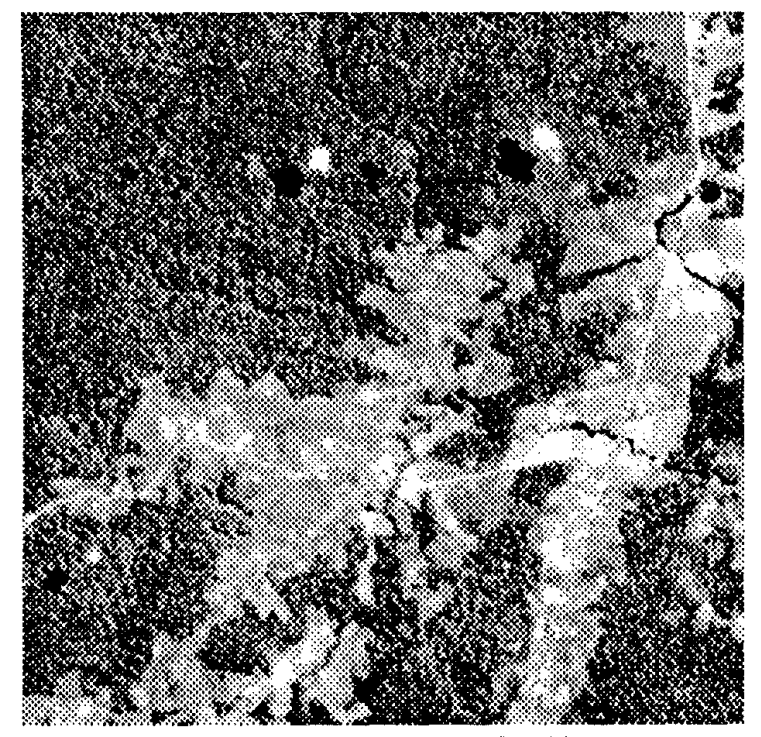

Fig. 1. First principal component, after histogram equalization.

\section{REFERENCES}

[1] G.J. Erthal, L.M.G. Fonseca, L.S. Bins, F.R.D. Velasco and A.M.V. Monteiro, "Um sistema de segmentação e classificação de imagens de satélite," in: Simpósio Brasileiro de Computação Gráfica e Processamento de Imagens, 4., São Paulo, SP, Brazil, 14-17 jul. 1991. Anais. SP, EPUSP, 1991, vol. 1, pp. 237-240.

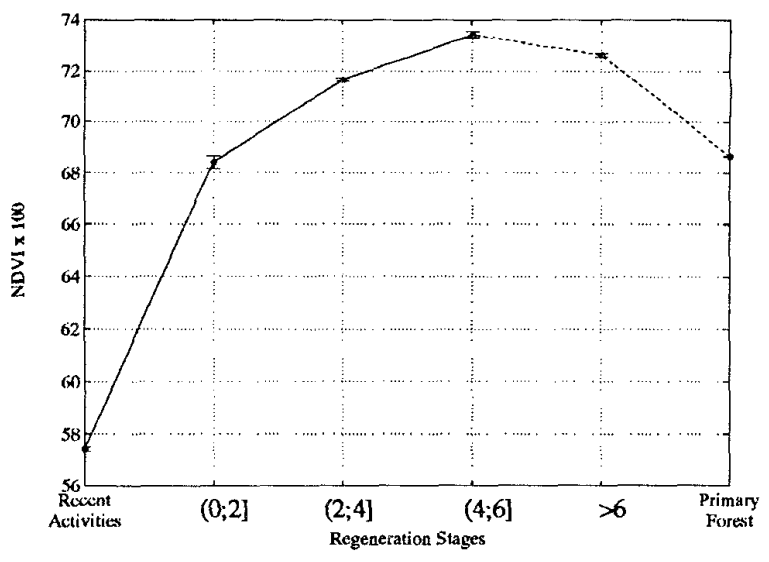

Fig. 2. Relationship between NDVI and stages of regeneration.

[2] P. Hernandez Filho, C.C.F. Yanasse, S.S. Sant'Anna, T.M. Kuplich, L.V. Dutra, P. Pessôa, A.C. Frery, and A.C. Abrahão, "Análise dos dados TM e descrição das atividades do trabalho de campo: Floresta Nacional de Tapajós", in press.

[3] S. Quegan et al., "ERS-1 observations and potential for use in tropical forest monitoring," in: TREES ERS-1 Study '94 Final Workshop, in press.

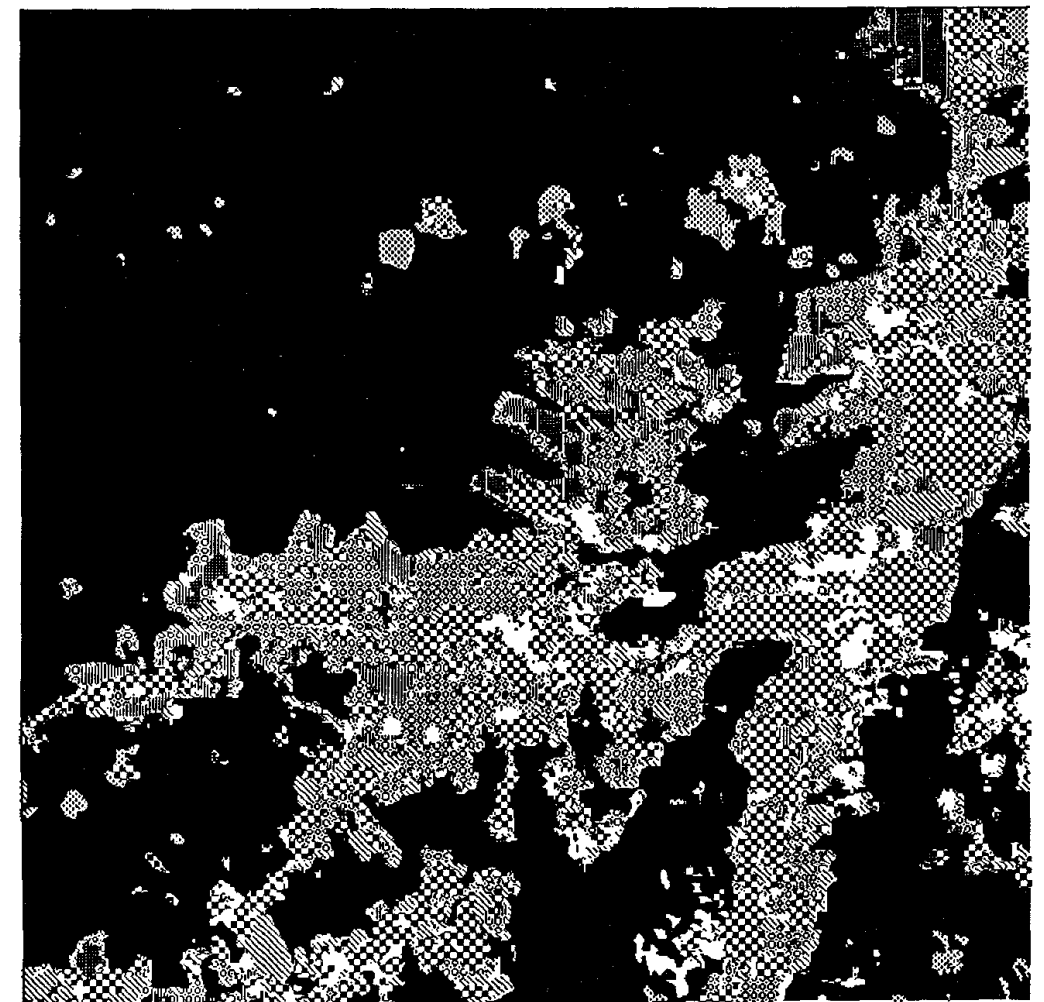

Fig. 3. Regeneration stages map.
8. Recent Activities

WN $(0 ; 2]$ Years Old

ing $(2 ; 4]$ Years Old

|l||| $(4 ; 6]$ Years Old

曲 More than Six Years Old

Primary Forest

Clouds and Shadows

No information available 